COURSES AND LECTURES No. 93

\author{
J. LITWINISZYN \\ MINING COLLEGE, CRACOW
}

\title{
STOCHASTIC METHODS IN MECHANICS OF GRANULAR BODIES
}

COURSE HELD AT THE DEPARTMENT

OF GENERAL MECHANICS

OCTOBER 1972

UDINE 1974 
This work is subject to copyright.

All rights are reserved,

whether the whole or part of the material is concerned

specifically those of translation, reprinting, re-use of illustrations,

broadcasting, reproduction by photocopying machine

or similar means, and storage in data banks.

(C) 1972 by Springer-Verlag Wien

Originally published by Springer-Verlag Wien-New York in 1972

ISBN 978-3-211-81310-2

ISBN 978-3-7091-2836-7 (eBook)

DOI 10.1007/978-3-7091-2836-7 
When discussing the mechanics of soil, rocks and loose media the models of the so called mechanics of continuous media are in general use. This model as sumes the invariant of the contact relations between the elements of the media. In case of the above media being in motion the invariant relation of the contacts is not maintained. Contacts between these elements change, the ordered relation is not maintained, and the elements intermingle. The motion of the medium is characterized by the mass character of random changes in contact relations and consequently by random displacement of the medium elements.

The movement of such a collection of elements depends on their mechanical properties only in a small degree, being mainly dependent on their spatial structure. Since the interaction of the elements has a mass and random character, the summary effect of displacements of elements is defined by random laws in agreement with the central limiting theorems.

These heuristic considerations suggest the idea of describing the displacements of a loose medium on the basis of a model different from the model of a model different from the model of a continuous medium. 
That model may be regarded as a system of integral equations which are generalizations of the smoluchowski equation describing the stochastic processes of the Markov type. In particular, from this system a parabolic system of differential equations, defining the mean values of displacement components of a loose medium, can be obtained.

Solutions for a number of cases of boundary conditions of this system have been given. The results have been compared with the displacement measurements obtained in experiments carried out in a loose medium in which the corresponding boundary conditions have been realized.

J. Litwiniszyn

Udine, October 1971 